\title{
ORAÇÃO CORRELATA COMPARATIVA: DO LATIM AO PORTUGUÊS
}

Prof. Dr. Márcio Luiz Moitinha Ribeiro (UERJ)

Prof. Me. Felipe de Andrade Constancio (UERJ)

RESUMO: A tradição gramatical latina - milenar, portanto - tem-nos oferecido a oportunidade de entender melhor a constituição estrutural e funcional das línguas vernaculares, entre elas o português. Este trabalho revisita um tópico que ainda oferece muitas discussões, na ordem do dia, em termos de articulação de orações, a saber: o estatuto das orações correlatas em evidência nos mais diversos manuais que lidam com a sintaxe do período composto. Esse estatuto é revisitado aqui de modo a direcionar esforços para o entendimento de como um tipo específico de correlatas - as comparativas - formaram-se até chegar ao que conhecemos, atualmente. Nesse breve percurso analítico, é sensato dizer que os adjetivos, em perspectiva diacrônica, tornaram-se as âncoras estruturais para que a comparação alcançasse a dimensão oracional, uma vez que a noção do grau semântico da classe dos adjetivos parece ter habilitado a formação das orações correlatas comparativas, em termos evolutivos.

PALAVRAS-CHAVE: comparação; correlação; sintaxe.

\section{COMPARATIVE RELATED CLAUSE: FROM LATIN TO PORTUGUESE}

\begin{abstract}
The Latin - millennial grammatical tradition, therefore - has offered us the opportunity to better understand the structural and functional constitution of the vernacular languages, including Portuguese. This paper revisits a topic that still offers many discussions, in terms of the articulation of clauses, namely: the status of related clauses in evidence in the most diverse manuals dealing with the syntax of the compound period. This statute is revisited here in order to direct efforts to understand how a specific type of correlates - the comparatives - were formed until we reach what we know today. In this brief analytical course, it is sensible to say that adjectives, in a diachronic perspective, became the structural anchors for the comparison to reach the orational dimension, since the notion of the semantic
\end{abstract}


degree of the adjective class seems to have enabled the formation of sentences comparative correlates, in evolutionary terms.

KEYWORDS: comparison; correlation; syntax.

\section{1 - Introdução}

A comparação entre gramáticas de uso vernacular português e gramáticas escritas para descrever o latim torna-se relevante para uma pesquisa desta envergadura, uma vez que põe em evidencia o tratamento de questões gramaticais que podem estar na ordem das permanências (o que se mantém como traço descritivo) e das rupturas (o que é inovador e particular na descrição dos objetos da língua).

Por conseguinte, o cotejo de gramáticas do latim e do português pode oferecer subsídios para um tratamento pormenorizado do adjetivo empiricamente observado em obras que, embora estejam em períodos distintos da história da língua, oferecem a oportunidade de sistematização da evolução de um item gramatical, tanto em termos de caracterização diacrônica quanto em termos de caracterização sincrônica.

A comparação entre gramáticas latinas e portuguesas pode oferecer, ainda, a oportunidade para que se compreenda, de modo científico, que a origem e a evolução de dado fenômeno linguístico são tópicos postos em pauta na agenda dos estudos linguísticos do século XXI. Dessa forma, está prevista, nessa agenda, a noção de que o entendimento originário e evolutivo de um sistema gramatical oferece um percurso consistente, na abordagem de determinado fenômeno gramatical.

O português, como língua originária do tronco indoeuropeu, pode ser "beneficiado" com pesquisas que apontam aspectos originários do tratamento gramatical de determinadas classes e funções. Nesse sentido, a gramática do português tornar-se-á fundamentada em dados empíricos à medida que avançarem os estudos a respeito dessas classes e funções, e consequentemente, progredirem as pesquisas diacrônicas e sincrônicas desses itens.

Embora este trabalho seja mais um esforço investigativo para a comparação de gramáticas de períodos distintos, como método científico, não se opera aqui com os fundamentos da Linguística Comparativa, tampouco com a sua abordagem teórica sugerida no século XIX. Desse modo, entende-se por comparação, neste trabalho, a noção de que o latim e 
o português assumem traços permanentes e de ruptura nas suas distintas abordagens circunscritas à história do pensamento gramatical do Ocidente.

$\mathrm{Na}$ tradição dos estudos linguísticos e gramaticais, o tratamento da morfologia mantevese restrito ao território dos estudos paradigmáticos (âmbito da forma), enquanto o tratamento da sintaxe manteve-se restrito ao eixo dos estudos sintagmáticos (âmbito da combinação). Pouco se investiu, portanto, no tratamento de questões gramaticais relacionadas à morfossintaxe.

Desse modo, um estudo que prevê um tratamento morfossintático (de forma e de combinação das formas) assume relevância, na medida em que fundamenta e põe em evidência determinadas unidades da língua e permite sua análise por meio de instrumentos concernentes à estrutura da forma e à compreensão de como essas unidades relacionam-se umas com as outras.

Assim, nos informa Castilho (CASTILHO, 2012, p. 69) sobre um recorte morfossintático da estrutura da língua: oferece também ferramentas mais consistentes ao analista da língua, na medida em que permite a observação de como certos itens gramaticais comportam-se não só morfologicamente mas também em contextos, como do nível da frase e de enunciados mais complexos. De modo geral, um tratamento morfossintático confere ao analista a oportunidade de se enxergar um objeto linguístico de maneira multissistêmica.

Infelizmente, as gramáticas latinas e portuguesas, de modo geral, investiram pouco em análises morfossintáticas de fenômenos linguísticos, o que nos legou a divisão gramatical de compêndios em morfologia e sintaxe. Desse modo, este trabalho torna-se também mais um investimento na compreensão de que a segregação de fenômenos linguísticos pela forma e pela combinação com outros itens oferece riscos a uma análise mais embasada do objeto a partir de suas múltiplas funções.

Esse pouco investimento na interface morfossintática impede, por vezes, que se façam análises concentradas tanto no domínio do léxico quanto no domínio da sintaxe. Cumpre notar, por exemplo, que conteúdos semânticos da gradação estão nos dois domínios, já que o vernáculo assume duas formas (afixos e orações) para estruturar dados de comparação (superioridade, inferioridade e igualdade).

De modo geral, torna-se relevante para este trabalho a natureza morfossintática do adjetivo e da oração comparativa, como objetos de análise gramatical em continuum. Um olhar investigativo para essas estruturas pode vir a ser uma chance de sinalizar que há mais 
traços em comum entre a morfologia e a sintaxe do que supõe toda a nossa tradição gramatical cujo interesse é seccionar essas supostas "partes” da gramática.

Uma análise de cunho morfossintático tanto em gramáticas latinas quanto em gramáticas do português pode, ainda, oferecer respostas ao analista no que concerne ao cotejo de determinado item gramatical em seu aspecto evolutivo e em sua conceituação sob distintos olhares teóricos.

\section{Gradação em adjetivos}

A questão seminal do grau dos adjetivos é tratada por Pierre Grimal (GRIMAL, 1986, p. 26 - 30) que nos apresenta o seguinte esquema:

Quadro 1: Natureza dos adjetivos

\begin{tabular}{|c|c|c|c|c|}
\hline \multirow{2}{*}{ Normal } & \multicolumn{2}{|c|}{ Comparativo } & \multicolumn{2}{c|}{ Superlativo } \\
\hline \multirow{3}{*}{$\begin{array}{c}\text { Exemplo: } \\
\text { Culto }\end{array}$} & de igualdade & tão culto & Relativo & Absoluto \\
\cline { 2 - 5 } & de superioridade & mais culto & o mais culto & $\begin{array}{c}\text { muito culto / } \\
\text { cultíssimo }\end{array}$ \\
\cline { 2 - 5 } & de inferioridade & menos culto & o menos culto & $\begin{array}{c}\text { pouquíssimo } \\
\text { culto }\end{array}$ \\
& & & & \\
\hline
\end{tabular}

As contribuições de Pierre Grimal (GRIMAL, 1986, p. 26), para o tratamento do grau dos adjetivos, em latim, em suma, restringem-se ao território da morfologia (embora haja também contribuições para o território da sintaxe). $\mathrm{O}$ autor sinaliza, em sua obra, a formação dos graus comparativo de superioridade, comparativo de igualdade e de inferioridade, superlativo de superioridade e superlativo de inferioridade.

Segundo o autor, o grau comparativo de superioridade forma-se ao se acrescentarem ao radical do adjetivo as formas -ior (masculino e feminino) e -ius (neutro). Assim, um adjetivo como "doctus" (culto) pode receber os sufixos - ior, -ius como em "doctior" / "doctius" (mais culto). Por outro lado, o grau comparativo de igualdade pode ser formado com as construções "tam minus ... quam" (tão menos... quanto/que) como em: "tam minus doctus quam...".

Ainda conforme Pierre Grimal (GRIMAL, 1986, p. 28), para formar o grau superlativo de superioridade, deve acrescentar-se à terminação do adjetivo o sufixo -issimus (ou -issima / 
-issimum), a saber: "doctus" (culto) e "doctissimus" (o mais culto). Por fim, o autor acrescenta a seguinte estratégia para a formação do grau superlativo de inferioridade: "usa-se o advérbio minime (o menos, pouquíssimo) antes do adjetivo: minime doctus (o menos culto)".

Com uma abordagem robusta acerca dos adjetivos, Paulo Rónai (RÓNAI, 2014, p. 30 31) compara a formação do grau dos adjetivos em latim e em português:

Ao passo que em português o comparativo de superioridade é uma expressão composta do advérbio "mais" e da forma do grau positivo (por exemplo: "mais alto"), em latim é tirado desta última por meio de sufixo.

Para formar o comparativo de superioridade, corta-se a terminação do genitivo singular do adjetivo masculino, e (...) acrescentam-se as terminações -ior para o masculino e feminino, -ius para o neutro. (RÓNAI, 2014, p. 30 - 31).

Como se pode observar, o autor supracitado (RÓNAI, 2014, p. 30 - 31) apresenta-nos um passo significativo em relação à passagem das peculiaridades do grau do adjetivo em latim para o português: o latim apresentava a peculiaridade do grau por meio de sufixo; e o português, por meio da sintaxe, desenvolveu expressões (de modo geral, locuções) para o mesmo conteúdo morfológico daquela língua.

Dessa forma, a abordagem do latinista (RÓNAI, 2014, p. 30 - 31) torna-se emblemática na medida em que se configura como um salto teórico, em termos diacrônicos, por priorizar a comparação de duas línguas cujos direcionamentos estruturais, em tese, distinguem-se em dois percursos descritivos díspares, a saber: um de natureza prototipicamente mórfica (o latim), e outro de natureza evolutiva ancorada na sintaxe (o português).

Assim como Paulo Rónai (RÓNAI, 2014, p. 30 -31), Márcio Ribeiro (RIBEIRO, 2017, p. 99 - 105) apresenta uma série de ponderações para sinalizar a interface morfossintática no tratamento do grau dos adjetivos. A partir do que desenvolve o gramático da UERJ (RIBEIRO, 2017, p. 99), temos o seguinte esquema, cuja culminância da gradação dos adjetivos repercute-se na integridade oracional:

Quadro 2: O adjetivo: perspectiva morfossintática

\begin{tabular}{|l|c|c|}
\hline \multicolumn{3}{|c|}{ Graus dos adjetivos } \\
\hline Positivo & Comparativo & Superlativo \\
\hline & "O irmão é mais fiel a Deus & \\
\hline
\end{tabular}




\begin{tabular}{|l|l|c|}
\hline \multirow{2}{*}{ "O irmão é fiel a Deus." } & do que o professor." & \multirow{2}{*}{$\begin{array}{l}\text { "O irmão é fidelíssimo a } \\
\text { do que o professor." }\end{array}$} \\
\cline { 2 - 2 } & $\begin{array}{l}\text { "O irmão é tão fiel a Deus } \\
\text { quanto o professor." }\end{array}$ & \\
\hline
\end{tabular}

Nesse sentido, a abordagem de Márcio Ribeiro (RIBEIRO, 2017, p. 99) sinaliza-nos que deve haver uma reanálise da formação do grau dos adjetivos pela via da perspectiva oracional. De modo geral, são raras as abordagens que mencionam um tratamento, não só morfológico, mas também sintático da gradação, na passagem do latim ao português.

\section{Gradação em orações}

O trabalho pioneiro de Maria Aparecida Pauliukonis (PAULIUKONIS, 1988, p. 13), sobre as orações correlatas comparativas, cuja análise incidiu sobre um texto latino de comédia, torna-se um mote para a pesquisa que ora se inicia. A abordagem da autora sinaliza, ainda no século $\mathrm{XX}$, que há uma linha bastante tênue entre o que se considera léxico e o que se considera sintaxe, de modo que há fenômenos da língua que podem ser observados, nesse limite.

Vejamos o que a tradição gramatical vernacular portuguesa reserva para o tratamento da comparação em perspectiva oracional.

Evanildo Bechara (BECHARA, 2009, p. 473) menciona as seguintes peculiaridades das orações complexas comparativas:

As subordinadas adverbiais do $2^{\circ}$ grupo, integradas pelas comparativas e consecutivas, guardam certa analogia com as adjetivas porque dependem de um antecedente, de natureza quantificadora ou de unidade quantificada (adjetivo ou advérbio) e só mantêm relação direta com o núcleo verbal da oração junto com seu antecedente.

Ainda que não rotule a questão da interdependência oracional, o autor salienta o fato de que as orações comparativas mantêm itens de natureza gramatical em ambos os membros oracionais. De fato, as estruturas comparativas, em formato oracional, operam com conectores 
(tão... quanto, tanto...quanto, mais... que, menos... que) cuja desmembramento é salutar para apontar, em alguns casos, o conteúdo semântico da gradação, perseguido, neste trabalho, em particular.

O tratamento de Evanildo Bechara (BECHARA, 2009, p. 474) direciona e nutre um olhar investigativo a respeito não só dos adjetivos que constituem as orações comparativas. Com um quadro sintético a respeito dos conectores responsáveis pela comparação oracional, o autor sugere que a gradação, em língua portuguesa, assume traços oracionais que dependem, por conseguinte, não só dos adjetivos, mas também do processo de gramaticalização de conjunções que engendram o processo da comparação.

Cunha e Cintra (CUNHA; CINTRA, 2017, p. 268) argumentam, com veemência, que as estruturas comparativas circunscritas aos adjetivos, por meio da gradação, podem ser expressas "em português por processos sintáticos ou morfológicos". O avanço dessa abordagem está, mais uma vez, implicado no tópico morfológico dos adjetivos, já que os autores sinalizam essa perspectiva morfossintática no território de formação das palavras de seu compêndio.

A respeito das orações comparativas e de uma possível omissão de termos, em sua estrutura, assim nos sugerem os autores supracitados:

Costuma-se omitir o predicado da oração subordinada comparativa, quando repete uma forma do verbo da oração principal. Assim: Teus olhos são negros, negros, / como as noites sem luar.../ (CUNHA; CINTRA, 2017, p. 622).

Embora mencionem a estrutura elidida ("como as noites sem luar são negras"), os autores não tratam a fundo a questão. Como leitores, pressupomos a noção de que há orações comparativas que omitem a estrutura verbo + adjetivo, uma vez que ela já está marcada na oração precedente. Como se pode notar, há também questões estilísticas tratadas de modo elementar, nas gramáticas vernaculares, como é o caso do texto de Cunha e Cintra (CUNHA; CINTRA, 2017, p. 622).

Em linhas gerais, o cotejo de compêndios latinos e vernaculares tem sinalizado um percurso cada vez mais estreito entre os processos de formação dos adjetivos e a estruturação de orações comparativas. Essa interface torna-se relevante, na medida em que certos 
"gatilhos" (formas) gramaticais têm sugerido, a nosso ver, as mesmas categorias semânticas (funções).

O regime peculiar de estruturação das orações comparativas no vernáculo (elas se estruturam pela via da correlação sintática ${ }^{1}$ ) tem-nos induzido a buscar estudos consistentes cujo interesse é o modo atípico por meio do qual essas orações conectam-se. Dessa forma, a reanálise de estruturas comparativas implica um investimento multissistêmico de formas, já que ganham realce formas cujo continuum do léxico à sintaxe oferece subsídios também consistentes ao analista da língua.

Para o tratamento de questões históricas, concernentes à passagem do latim ao português, tornam-se pertinentes as seguintes abordagens: Ismael Coutinho (COUTINHO, 1976, p. 29 - 34) aponta, por meio de análise diacrônica, processos morfológicos em interface com questões sintáticas fartamente exemplificadas ao longo de sua abordagem; ainda no território filológico, Segismundo Spina (SPINA, 2008, p. 282) elabora um texto monumental para tratar da estrutura gramatical latina, em seus aspectos evolutivos.

Como se vê, um estudo de natureza histórica, como o que se propõe, não parte de uma perspectiva pouco explorada. Muitos são os olhares em torno de questões morfossintáticas e, sem sombra de dúvida, um olhar investigativo em cotejo (justamente a passagem do latim ao português) tem muito a oferecer aos estudos gramaticais contemporâneos, em termos propositivos.

\section{Correlação em perspectiva gramatical}

A seguir, pontua-se uma breve incursão a respeito do tratamento que recebem as orações correlatas no seio de correntes teóricas distintas. Para nortear esse tratamento, operase um recorte cujo limite está pautado, na análise das orações correlatas, em três perspectivas: a gramatical, a funcional e a enunciativa.

Conforme salienta Violeta Virgínia Rodrigues (RODRIGUES, 2014, p. 225):

A abordagem adotada por gramáticos de linha tradicional apresenta como processos de articulação de orações no período a coordenação e a subordinação - e a possibilidade de a coordenação e a subordinação ocorrerem

\footnotetext{
${ }^{1}$ Embora haja um avanço nos estudos recentes a respeito da correlação sintática, cabe mencionar que muitas orações correlatas ainda são tratadas no âmbito da subordinação, com é o caso das comparativas.
} 
simultaneamente -, desconsiderando outros tipos de categorias na estruturação do período composto.

Nesse quadro teórico que por vezes negligencia o estatuto gramatical de orações correlatas, negando-lhes o reconhecimento estrutural e funcional, é possível encontrarem-se iniciativas descritivas de variadas naturezas. A seguir, delineiam-se algumas dessas iniciativas circunscritas a correntes normativas, textuais e descritivas em relação à abordagem das orações correlatas.

Em José Oiticica (OITICICA, 1962, p. 13), há uma reflexão pioneira a respeito da correlação que podemos atestar, na seguinte passagem: "esse processo de composição do período, até aparecer o Manual, sempre andou confundido com o da subordinação em todas as gramáticas brasileiras ou estrangeiras". Expandindo essa reflexão, se pode dizer que a correlação, como processo sintático, é representada em compêndios gramaticais mais tradicionais (anteriores e posteriores à Nomenclatura Gramatical Brasileira) no interior também de orações coordenadas.

A interdependência sintática sugerida por pares de orações correlatas, em sua maioria, apenas recebe um tratamento direcionado à sua constituição estrutural, a saber: apenas salientam-se as peculiaridades dos conectivos correlatos (“ou... ou", "não só... mas também”, "tanto... quanto" etc.). A descrição operada por esses compêndios parece não ultrapassar a fronteira estrutural de orações correlatas representadas nos processos coordenação e subordinação.

Na perspectiva estilístico-textual de Othon Garcia (GARCIA, 2010, p. 54), as orações correlatas são estudadas a partir de seu suposto "equilíbrio" para a construção dos períodos. O autor investe, sobremaneira, no tratamento das orações correlatas de valor semântico aditivo construídas por meio de "não só... mas também" e outras estruturas afins. O interesse conduzido pela obra de Othon Garcia (GARCIA, 2010, p. 54) encaminha a noção de que esse tipo de estrutura é responsável por criar tensão discursiva, o que caracteriza o monitoramento argumentativo de um falante ou escritor que se vale desse tipo de estrutura.

O autor supracitado (GARCIA, 2010, p. 54) discorre sobre a expressão "não só mas também" e sua relação com o paralelismo estrutural. Vejamos: "esse par correlato - "não só... mas também' - exige quase sempre paralelismo estrutural das expressões que se seguem a cada um dos elementos que o constituem". Essa abordagem das orações correlatas torna-se 
também pioneira, na medida em que concebe esse processo gramatical, na ótica dos estudos textuais, no sentido de que atribui a esses estudos uma ótica estilística ao tratamento da correlação.

Evanildo Bechara (BECHARA, 2009, p. 479) atribui às orações correlatas organizadas por coordenação a designação "coordenação distributiva", como se vê, abaixo:

Podem-se incluir nas orações justapostas aquelas que a gramática tradicional arrola sob o rótulo de coordenadas distributivas, caracterizadas por virem enlaçadas pelas unidades que manifestam uma reiteração anafórica do tipo ora...ora, já...já, quer...quer, um...outro, este...aquele, parte...parte, seja...seja, e que assumem valores distributivos alternativos, e subsidiariamente concessivos, temporais, condicionais.

A abordagem do gramático (BECHARA, 2009, p. 479) não deixa igualmente de mencionar o caráter estruturante do texto, operado por certas estruturas correlativas. Veja-se, portanto, que a correlação assume viés anafórico, nas palavras do autor, uma vez que, além de possibilitar o encadeamento oracional, esse tipo de composição de orações torna-se reiterativo para o encadeamento de informações textuais.

Em Cunha e Cintra (CUNHA; CINTRA, 2008, p. 623), a correlação figura apenas como observação no tratamento de orações subordinadas: "Estas orações podem estar em correlação com um membro da oração principal em construções do tipo: quanto mais... tanto mais, quanto mais... tanto menos, quanto menos... tanto menos, quanto menos... tanto mais".

Não há neles (CUNHA; CINTRA, 2008, p. 623) uma abordagem explícita a respeito da distribuição das orações correlatas entre as orações coordenadas e subordinadas. Nem mesmo uma abordagem semântica é mencionada a partir dos possíveis usos de orações correlatas no período composto. Como se vê, em obras cujo tratamento aproxima-se consideravelmente de uma possível ótica pró-Nomenclatura Gramatical Brasileira, não são levados em conta tópicos específicos para a descrição sintático-semântica de orações correlatas.

$\mathrm{Na}$ esteira dos estudos descritivos mais recentes, José Carlos de Azeredo (AZEREDO, 2011, p. 351) aborda a correlação por meio da seguinte ótica: "processo usual na linguagem da argumentação, utilizado para dar idêntico realce às unidades conectadas". Do mesmo modo que outros autores, José Carlos de Azeredo (AZEREDO, 2011, p. 351) não atribui às orações correlatas a peculiaridade de compor um processo sintático distinto da coordenação e da subordinação. 
Nesse sentido, a contribuição que a abordagem de José Carlos de Azeredo (AZEREDO, 2011, p. 351) confere à correlação num esforço de consideração dessa estrutura no âmbito de processos argumentativos, nos quais o enunciador de um texto vale-se de uma estruturação do período para fins discursivos altamente monitorados. Vejamos o que diz ainda o autor (AZEREDO, 2011, p. 351):

A maior parte das palavras gramaticais que a realizam é emprestada de outras classes, como os advérbios tanto e quanto, mais e também. A correlação é um expediente retórico, de rendimento enfático no discurso, e não um processo sintático distinto da coordenação e da subordinação.

Seguindo o viés dos estudos descritivos mais recentes, Ataliba Teixeira de Castilho (CASTILHO, 2012, p. 385) pontua que, ao lado da coordenação e da subordinação, a correlação figura como "um terceiro tipo de relações intersentenciais". Pela ótica desse autor (CASTILHO, 2012, p. 387), determinadas orações correlatas, como as alternativas, não devem ser enquadradas como orações coordenadas: "não é adequado tratar as aditivas e as alternativas exclusivamente como coordenação, nem as comparativas e as consecutivas como subordinadas adverbiais.

Para sistematizar a abordagem das orações correlatas, em perspectivas gramaticais distintas, segue o Quadro 3, na próxima página:

Quadro 3: Conceituação de correlação

\begin{tabular}{|l|l|}
\hline \multicolumn{1}{|c|}{ AUTORES } & \multicolumn{1}{|c|}{ ABORDAGENS } \\
\hline Oiticica (1962, p. 13) & $\begin{array}{l}\text { “...) esse processo de composição do } \\
\text { período, até aparecer o Manual, sempre } \\
\text { andou confundido com o da subordinação em } \\
\text { todas as gramáticas brasileiras ou } \\
\text { estrangeiras”. }\end{array}$ \\
\hline Garcia (2010, p. 54) & $\begin{array}{l}\text { “(..) esse par correlato - 'não só... mas } \\
\text { também' - exige quase sempre paralelismo } \\
\text { estrutural das expressões que se seguem a } \\
\text { cada um dos elementos que o constituem”. }\end{array}$ \\
\hline
\end{tabular}




\begin{tabular}{|c|c|}
\hline Bechara $(2009$, p. 479) & $\begin{array}{l}\text { "Podem-se incluir nas orações justapostas } \\
\text { aquelas que a gramática tradicional arrola } \\
\text { sob o rótulo de coordenadas distributivas, } \\
\text { caracterizadas por virem enlaçadas pelas } \\
\text { unidades que manifestam uma reiteração } \\
\text { anafórica do tipo ora...ora, já...já, } \\
\text { quer...quer, um...outro, este...aquele, } \\
\text { parte...parte, seja...seja, e que assumem } \\
\text { valores distributivos alternativos, } \\
\text { subsidiariamente concessivos, temporais, } \\
\text { condicionais". }\end{array}$ \\
\hline Cunha e Cintra (2008, p. 623) & $\begin{array}{l}\text { "Estas orações podem estar em correlação } \\
\text { com um membro da oração principal em } \\
\text { construções do tipo: quanto mais... tanto } \\
\text { mais, quanto mais... tanto menos, quanto } \\
\text { menos... tanto menos, quanto menos... tanto } \\
\text { mais". }\end{array}$ \\
\hline Azeredo (2011, p. 351) & $\begin{array}{l}\text { “(..) processo usual na linguagem da } \\
\text { argumentação, utilizado para dar idêntico } \\
\text { realce às unidades conectadas". }\end{array}$ \\
\hline Castilho $(2012$, p. 385) & $\begin{array}{l}\text { "(...) um terceiro tipo de relações } \\
\text { intersentenciais". }\end{array}$ \\
\hline
\end{tabular}

\section{Correlação em perspectiva funcional}

A gramática funcional, que tem como principal representante o linguista britânico M. A. K. Halliday, pode ser definida, segundo sugere Maria Helena de Moura Neves (NEVES, 1997, p. 15), da seguinte forma:

Por gramática funcional entende-se, em geral, uma teoria da organização gramatical das línguas naturais que procura integrar-se em uma teoria global da interação social. Trata-se de uma teoria que assenta que as relações entre as 
unidades e as funções das unidades têm prioridade sobre seus limites e sua posição, e que entende a gramática como acessível às pressões do uso.

Dessa forma, as unidades da gramática, citadas por Maria Helena de Moura Neves (NEVES, 1997, p. 15), assumem uma outra configuração, na medida em que constituem o sistema, mas, na verdade, estão sujeitas a "pressões do uso", o que equivale dizer que morfemas, palavras, sintagmas, orações e períodos, como unidades linguísticas, são descritas pela gramática funcional de modo a privilegiar os usos subjacentes às suas peculiaridades dentro do sistema.

Ainda de acordo com a autora (NEVES, 1997, p. 22), o objetivo dessa proposta funcional é "explicar regularidades dentro das línguas", levando em consideração o fato de que existem "circunstâncias sob as quais as pessoas usam a língua". Vale ressaltar que, como vertente teórico-metodológica, esse tipo de gramática ocupa posição intermediária entre abordagens que visam somente à sistematicidade ou à mera instrumentalidade da língua.

Nesse sentido, duas questões, entre outras, mostram-se relevantes, por se colocarem como centrais nos estudos das investigações funcionalistas, conforme ela aponta (NEVES, 2013, p. 17):

(...) relações entre discurso e gramática (porque o discurso conforma a gramática, mas principalmente porque ele não é encontrável despido da gramática;

liberdade organizacional do falante, dentro das restrições construcionais (porque o falante processa estruturas regulares, mas é ele que faz as escolhas que levam a resultados de sentido e a efeitos pragmáticos).

Dentro do quadro teórico da gramática funcional, torna-se nítida a noção de que uma descrição coerente dos elementos da língua deve levar em consideração fatores pragmáticos, já que existe uma certa indissociabilidade entre gramática e pragmática. Esta última corrente teórica surgiu dos estudos mais recentes da Análise do Discurso, no século XX, e, aliada ao Funcionalismo, trouxe contribuições relevantes à concepção funcional de sintaxe.

$\mathrm{Na}$ gramática funcional, "a sintaxe é vista”, segundo Maria Helena de Moura Neves (NEVES, 1997, p. 24), “como a codificação de dois domínios funcionais distintos: a semântica (proposicional), cujo enfoque busca a codificação das unidades da língua 
(sintagma, oração, período), e a pragmática (discursiva), cujo enfoque busca a significação das unidades da língua em condições de uso linguístico.

Ivo Rosário (ROSÁRIO, 2015, p. 151) aplica os preceitos teóricos da gramática de vertente funcionalista ao estudo do processo sintático da correlação. O funcionalista Ivo Rosário (ROSÁRIO, 2015, p. 151) menciona que: “a correlação, salvo raras exceções, fica diluída nos capítulos destinados à investigação da sintaxe do período composto, sem um tratamento mais minucioso e aprofundado".

Recortando especificamente as orações correlatas aditivas, (como em "não só... mas também”), o linguista (ROSÁRIO, 2015, p. 152) vale-se de um gênero textual, os discursos políticos, para observar as ocorrências de pares correlativos aditivos. Baseando-se numa análise quantitativa de dados, o autor chega a resultados muito aprofundados a respeito das estruturas prototípicas desse tipo de correlação.

Estudos desta natureza são, portanto, raros no território de teorização gramáticofuncional, na medida em que muito já se disse sobre a coordenação e a subordinação, mas pouco se investiu em pesquisas acerca das peculiaridades sintático-discursivas das orações correlatas.

Segundo Ivo Rosário (ROSÁRIO, 2015, p. 159), a incidência de estruturas correlatas aditivas em discursos políticos é um fator que ratifica a noção de que esse tipo de gênero textual é ancorado por estruturas argumentativas em potencial:

Assim, a observação dos dados permite-nos observar que a correlação está a serviço, principalmente, de uma maior explicitação dos conteúdos desenvolvidos ao longo do texto, pelo menos, de caráter argumentativo.

Com base na investigação desses dados, podemos fazer duas importantes constatações. Em primeiro lugar, comprovamos que os padrões correlativos aditivos não podem ser simplesmente reunidos em um grupo único chamado coordenação aditiva. (...)

Dessa forma, estudos, como o de Ivo Rosário (ROSÁRIO, 2015, p. 159), ensejam investigações cujo enfoque direciona um duplo encaminhamento a respeito das orações correlatas: entram em jogo, nos usos linguísticos, as motivações subjacentes à própria noção de língua, como fator de veiculação de significados ancorados em unidades concretas da gramática; tornam-se mais estreitas as relações entre unidades da gramática e modos de organização do discurso, no sentido de que estes concretizam aquelas. 


\section{Correlação em perspectiva enunciativa}

Em linhas gerais, a Linguística da Enunciação é uma corrente teórica dos estudos da linguagem cujos preceitos não se distanciam das noções de que a língua está fortemente relacionada aos seus condicionamentos funcionais e, sobretudo, de que a língua comporta um potencial subjetivo.

Conforme aponta Valdir Flores (FLORES, 2013, p. 67), os primeiros estudos, na área da enunciação, foram empreendidos por Émile Benveniste, cujo interesse pelos fatores de subjetividade, no território da linguagem, começou a fomentar outros estudos enunciativos. Ainda segundo Valdir Flores (FLORES, 2013, p. 67), “aprofundam-se estudos sobre a Teoria da Enunciação, de Benveniste, dando-se destaque à língua, em funcionamento, ou seja, à língua inteira vista sob a perspectiva enunciativa.

Correntes mais recentes da Análise do Discurso têm investido, nessa ótica, de que a língua é condicionada por meio dos usos. Uma das teorias que dialoga com esse condicionamento é a Teoria Semiolinguística, proposta por Patrick Charaudeau (CHARAUDEAU, 2016, p. 21). De acordo com essa teoria, dois campos de investigação são postos à prova, no estudo dos fatos da linguagem, a saber: a Semiótica e a Linguística.

Vejamos o que diz Patrick Charaudeu (CHARAUDEAU, 2016, p. 21) a respeito desses campos:

(...) diremos que uma análise semiolinguística do discurso é Semiótica pelo fato de que se interessa por um objeto que só se constitui em uma intertextualidade. Esta última depende dos sujeitos da linguagem, que procuram extrair dela possíveis significantes. Diremos também que uma análise semiolinguística do discurso é Linguística pelo fato de que o instrumento que utiliza para interrogar esse objeto é construído ao fim de um trabalho de conceituação estrutural dos fatos linguageiros.

De posse desses direcionamentos teóricos, Patrick Charaudeu (CHARAUDEAU, 2016, p. 201) investe na teorização dos modos de organização do discurso, cujo fundamento voltase, sobremaneira, para o fato de que as atividades linguageiras materializam unidades de língua responsáveis não pela representação do mundo, mas pela construção de unidades da língua, em constante processo de significação. 
Para subsidiar o tratamento das orações correlatas pela ótica da Teoria Semiolinguística, recorre-se, nesta proposta, à abordagem de Patrick Charaudeau (CHARAUDEAU, 2016, p. 201) a respeito do modo de organização argumentativo. Assim nos informa o autor: "a argumentação, entretanto, é um setor de atividade da linguagem que sempre exerceu fascínio, desde a retórica dos antigos que dela fizeram o próprio fundamento das relações sociais (...)”.

Conceber a correlação como uma manifestação estrutural decorrente do modo de organização argumentativo implica reconhecer que existem fatos linguageiros condicionantes do uso da língua duplamente projetado para o convencimento e a persuasão. Dessa forma, os fatos linguageiros circunscritos ao âmbito do convencimento projetam estruturas argumentativas da ordem da lógica; os fatos linguageiros circunscritos ao âmbito da persuasão costumam projetar estruturas atreladas à subjetividade/afetividade.

De modo geral, a correlação, como estrutura gramatical, veicula, tanto na esfera do convencimento, quanto na esfera da persuasão, matizes significativos que convergem para a manifestação, prototipicamente monitorada, do modo de organização argumentativo. Além da manifestação explícita desse modo de organização discursivo, outros condicionantes discursivos implícitos são subjacentes à correlação, como é o caso da modalização.

De acordo com a Teoria da Enunciação, a modalização está relacionada às marcas ideológicas impressas por um sujeito ao seu enunciado. De certa maneira, as orações correlatas assumem marcas enunciativas de modalização, quando acionam unidades de língua de comprometimento.

As orações correlatas de valor alternativo tendenciam, portanto, marcas de modalização enunciativa, na medida em que sugerem, no modo de organização discursivo argumentativo, posicionamentos que, em sua maioria, estão na ordem do que se costuma designar proteção de face ou menor assertividade enunciativa.

Veja-se o que declara Maria Aparecida Pauliukonis (PAULIUKONIS, 2003, p. 41) sobre a modalização: “Aceitando-se como tácito que o sujeito enunciador é construído pelo discurso, por meio de marcas visíveis na enunciação, poder-se-ia perguntar de que tipo seriam essas marcas ou se elas já não foram suficientemente codificadas pela tradição".

Um estudo que visa à apreensão das marcas de modalização, em orações correlatas, mostra-se promissor, no sentido de que é direcionado pelas perspectivas funcional e enunciativa. Em linhas gerais, se pode dizer que esses direcionamentos teóricos têm 
contribuições pertinentes para uma descrição mais coerente desse processo oracional, em português.

\section{Orações correlatas comparativas}

Embora sejam tratadas, neste trabalho, como orações correlatas, as orações comparativas são contempladas, no quadro descritivo das orações adverbiais, na tradição gramatical latina. Uma prova de que essas orações são consideradas adverbiais está, em Paulo Sérgio de Vasconcellos (VASCONCELLOS, 2013, p. 124):

As orações subordinadas adverbiais comparativas/conformativas integram uma estrutura comparativa (introduzindo o segundo termo da comparação de igualdade, inferioridade ou superioridade ou tecendo uma comparação mais sutil entre os dois enunciados, como quando se expressa que um processo ocorreu conforme previa um outro ou quando a subordinada introduz um exemplo).

Como se atesta, não se menciona explicitamente o caráter correlativo, nesse tipo oracional. Nos exemplos de pares oracionais comparativos, o autor menciona os tipos de disjunção comuns, na comparação, como em "tam... quam: tão... quão/quanto" (VASCONCELLOS, 2013, p. 125).

Por essa razão, pode-se, indubitavelmente, aproximar o tratamento sintático das orações adverbiais comparativas, tanto no latim, quanto no português, com as orações correlatas, uma vez que é notória a transposição da análise sintática empreendida, nas duas estruturas, de modo que o autor, em vários exemplos (muitos de Cícero), situa-nos em moldes sintagmáticos, em nada, distantes do herdado em Língua Portuguesa. A estrutura comparativa empiricamente não parece ter sofrido mudanças sintáticas, pelo menos não em termos correlativos.

Ainda que não mencione claramente o caráter correlativo das estruturas comparativas, Paulo Sérgio de Vasconcellos (VASCONCELLOS, 2013, p. 127) trata especificamente dos adjetivos e dos advérbios que compõem essas orações, o que situa a hipótese elencada, no início deste trabalho, de que os adjetivos, sobretudo os superlativos, podem constituir o primeiro estágio, na origem das orações correlatas comparativas. 
Segundo o autor, há estruturas comparativas "com adjetivos e advérbios indicando semelhança ou diferença" nas quais "aparece a conjunção ac/atque, a saber: indicando semelhança (aeque ac/atque: "de maneira igual") e indicando diferença (alius ac/atque: "diverso de"). Desse modo, se pode concluir que a tradição gramatical latina, ao sugerir o adjetivo como base da estrutura comparativa, oferece-nos a oportunidade de resgatar as noções igualdade, inferioridade e superioridade, presente nos compêndios da tradição gramatical do português.

A obra de Paulo Sérgio de Vasconcellos (VASCONCELLOS, 2013, p. 127), pela sua abordagem, oferece-nos um viés descritivo em que se pode observar um salto no tratamento das chamadas orações adverbiais, já que o pesquisador investe no fato de que existem conectores correlativos (conjunções/locuções conjuntivas) indubitavelmente relacionados ao adjetivo para que haja a estruturação dos pares correlatos.

De modo distinto, Gladstone Chaves de Melo (MELO, 2001, p. 152) pontua: “já dissemos que, dissentindo da NGB, consideramos a correlação como um terceiro processo sintático" e acrescenta que "a correlação pode ser consecutiva, comparativa, equiparativa e alternativa”. Diferentemente de outros autores, o autor supracitado (MELO, 2001, p. 152) inaugura um tratamento da comparação que não se atrela às orações adverbiais:

Na correlação comparativa quase sempre se cala o predicado do segundo termo, por menor esforço, porque tal predicado é o mesmo da primeira oração: "Josélia é mais prendada que Nair [é prendada]"; "Pedro comprou mais na feira do que Vítor [comprou]"; "Antônio Luís é tão piedoso e religioso quanto João [é piedoso e religioso]".

Por meio dessa ótica, o filológo (MELO, 2001, p. 152) descreve a correlação comparativa como um estatuto à parte, diferenciando-a da formação estrutural das chamadas orações adverbiais. Essa postura teórica pode ser entendida como inovadora, uma vez que ele (MELO, 2001, p. 152) se situa como um teórico reconhecido por operar uma descrição tradicional do português, em que muitos exemplos descritivos, inclusive das chamadas orações correlatas comparativas, são retirados de corpus literário.

Endossando a nossa hipótese inicial, Gladstone Chaves de Melo (MELO, 2001, p. 72 73) tece considerações sobre o grau dos adjetivos em comum acordo com a descrição das orações correlatas comparativas. Embora trate do adjetivo e, consequentemente, da gradação 
em capítulo restrito ao âmbito da morfologia, o autor menciona, de modo bastante pontual, o fato de que há evidências em relação à natureza do adjetivo analítico/sintético, como item morfológico e evolutivo, cuja contribuição à formação da estrutura comparativa é inegável.

Assim menciona (MELO, 2001, p. 72-73):

Podemos agora sistematizar. O comparativo pode ser de superioridade, de igualdade e de inferioridade. $\mathrm{O}$ de superioridade forma-se com o auxílio do advérbio "mais" (analítico) ou com palavras especiais, como maior, melhor, e tem o segundo termo regido de "que" ou "do que".

O comparativo de igualdade forma-se com o auxílio do advérbio "tão", ficando o segundo termo regido de "quanto" ou "como": "Alzira é tão caprichosa quanto (como) Teresinha".

O comparativo de inferioridade forma-se com o auxílio do advérbio "menos", ficando o segundo termo regido de "que" ou "do que": "Afonso é menos nervoso que (do que) Celso".

Em linhas gerais, a abordagem do saudoso filólogo da ABRAFIL ${ }^{2}$ (MELO, 2001, p. $72-$ 73) corrobora a nossa hipótese inicial de que a estrutura correlata comparativa, herdada pelo português, porta marcas morfossintáticas presentes, na estrutura do adjetivo, com registro no latim, sobretudo, no que diz respeito à gradação, como um fator de natureza não só derivacional como também sintática e como um traço evolutivo, na passagem dessa língua àquela.

\section{Considerações finais}

A proposição de um trabalho desta natureza, cuja pretensão é a revisão e o redirecionamento da abordagem das orações correlatas, corrobora a noção de que existem lacunas consideráveis em relação ao tratamento desse item gramatical no âmbito da sintaxe do período composto. Uma revisão teórica que perpassa os domínios da gramática (normativa, descritiva e funcional) aponta diretrizes para uma interpretação estrutural mais consistente das orações correlatas comparativas.

Não é recente a noção de que as categorias gramaticais de língua podem ser estudadas em confronto com as categorias de significado. Essa possibilidade de diálogo prevê, de modo geral, que os significados (decorrentes dos fatores discursivos) materializam-se nas categorias

\footnotetext{
${ }^{2}$ Academia Brasileira de Filologia.
} 
estruturais de uma determinada língua (decorrentes de fatores gramaticais), nesse caso o português.

Na interface língua e história, o português sugere-nos, em seu diálogo com o latim, nos seus mais variados registros, a oportunidade de investigar manifestações estruturais da língua provenientes de fatores da ordem do sentido. Dessa forma, um estudo baseado, nessa interface traz duas contribuições ao analista, a saber:

a) dá-lhe a oportunidade de revisitar categorias ou estatutos gramaticais negligenciados, na história dos estudos linguísticos;

b) oferece-lhe ferramentas de análise para observar com mais exatidão o fenômeno linguístico.

Nessa linha propositiva, o objeto de estudo sugerido, neste trabalho, investigou brevemente o estatuto gramatical da correlação. Como ocorre com a subordinação, coordenação e justaposição, os estudos descritivos, voltados à investigação dos usos, em torno do estatuto da correlação, embora sejam fomentados, não são tão numerosos. Dessa forma, os estudos sobre orações correlatas, na perspectiva dos seus registros históricos/funcionais, ainda são raros em Língua Portuguesa.

Em linhas gerais, o funcionalismo oferece um aporte teórico sem o qual seria impossível investigar os fenômenos linguísticos fora do seu contexto de situação ou de cultura. A perspectiva funcional não desvincula, portanto, as categorias de língua fora de seu contexto histórico e de uso.

Para o funcionalismo, o estatuto gramatical da correlação comparativa aciona formas gramaticais tensas (bastante monitoradas) para conteúdos que, por vezes, implicam graus (como herança estrutural dos adjetivos) variados, na construção da sentença. Na ótica funcional, as orações correlatas comparativas recebem um tratamento, não apenas estrutural, mas igualmente circunscrito à esfera da sua origem evolutiva, como item da língua.

Nesse sentido, a presente pesquisa, longe de esgotar o tratamento das orações correlatas, traz breves considerações a respeito desse tópico da gramática, o que não impede uma investigação mais pontual acerca dos fatores diacrônicos implicados, na formação de estruturas comparativas. Por ora, se pode salientar que a investigação aqui iniciada pode abrir espaço a intervenções e interfaces, no estudo do latim e do português, em perspectiva histórica. 


\section{Referências bibliográficas}

AZEREDO, José Carlos de. Gramática Houaiss da língua portuguesa. São Paulo: Publifolha, 2011.

BECHARA, Evanildo. Moderna gramática portuguesa. Rio de Janeiro: Nova Fronteira, 2009.

CASTILHO, Ataliba Teixeira de. Nova gramática do português brasileiro. São Paulo: Contexto, 2012.

CHARAUDEAU, Patrick. Linguagem e discurso: modos de organização. Tradução: Angela M. S. Corrêa. 2. ed. São Paulo: Contexto, 2016.

CINTRA, Luis Filipe Lindley; CUNHA, Celso. Nova gramática do português contemporâneo. Rio de Janeiro: Lexikon, 2017.

Nova gramática do português contemporâneo. 5. ed. Rio de Janeiro: Lexikon, 2008.

COUTINHO, Ismael de Lima. Gramática histórica. Rio de Janeiro: Ao livro técnico, 1976.

FLORES, Valdir do Nascimento et al. "Uma linguística da enunciação". In: FLORES, Valdir do Nascimento et al. Enunciação e gramática. 2. ed. São Paulo: Contexto, 2013.

GARCIA, Othon Moacyr. Comunicação em prosa moderna: aprenda a escrever, aprendendo a pensar. 27. ed. Rio de Janeiro: Editora FGV, 2010.

GRIMAL, P. et al. Gramática latina. Tradução: Maria Evangelina Soeiro. São Paulo: T. A. Queiroz/EDUSP, 1986.

MELO, Gladstone Chaves de. Gramática fundamental da língua portuguesa. 4. ed. Rio de Janeiro: Ao livro técnico, 2001.

NEVES, Maria Helena de Moura. A gramática funcional. São Paulo: Martins Fontes, 1997. Texto e gramática. 2. ed. São Paulo: Contexto, 2013.

OITICICA, José. Teoria da correlação. 2. ed. Rio de Janeiro: Organização Simões, 1962.

PAULIUKONIS, Maria Aparecida Lino. "Marcas discursivas do enunciador midiático: casos de modalização autonímica". In: GAVAZZI, Sigrid; PAULIUKONIS, Maria Aparecida Lino (org.). Texto e discurso: mídia, literatura e ensino. Rio de Janeiro: Lucerna, 2003.

As estruturas correlatas da comparação: análise semântico-argumentativa do discurso na Comédia Eufrosina. Tese de Doutorado em Letras Vernáculas, Rio de Janeiro: UFRJ, 1988. 
RIBEIRO, Márcio Luiz Moitinha. Gramática latina: ampliada com a morfologia histórica das declinações. Rio de Janeiro: Márcio Moitinha Editora, 2017.

RODRIGUES, Violeta Virginia. "Correlação”. In: BRANDÃO, Silvia Figueiredo; VIEIRA, Silvia Rodrigues (org.). Ensino de gramática: descrição e uso. 2. ed. São Paulo: Contexto, 2014.

Curso básico de latim: gradus secundus. São Paulo: Cultrix, 2014.

ROSÁRIO, Ivo. "Sintaxe funcional”. In: KENEDY, Eduardo; OTHERO, Gabriel de Ávila (org.). Sintaxe, sintaxes: uma introdução. São Paulo: Contexto, 2015.

SPINA, Segismundo (org.). História da língua portuguesa. Cotia, SP: Ateliê Editorial, 2008.

VASCONCELlOS, Paulo Sérgio de. Sintaxe do período subordinado latino. São Paulo: Editora Fap - Unifesp, 2013. 